\title{
CHLOROQUINE RETINOPATHY IN NIGERIAN PATIENTS WITH HEART BLOCK
}

\author{
N. O. MAGULIKE ${ }^{1}$, H. N. C. IHENACHO ${ }^{2}$ and V. O. IKE $^{2}$ \\ Enugu, Nigeria
}

\begin{abstract}
SUMMARY
Twenty-six patients with heart block were examined for evidence of chloroquine retinopathy. Detailed histories of chloroquine intake showed that $50 \%$ (13 of 26) of these patients were chloroquine abusers. Retinal changes typical of chloroquine retinopathy were seen in $53.8 \%$ ( 7 of 13) of the chronic chloroquine abusers. Patients with heart block of unknown cause should have their fundi examined so that signs of chloroquine retinopathy may be sought.
\end{abstract}

Since the initial report of chloroquine retinopathy by Hobbs et al. in $1959^{1}$, numerous descriptions of this condition have been published. ${ }^{2-7}$ The eye, spleen, liver and kidney are known to retain higher levels of chloroquine than plasma, but knowledge of the chronic toxic effect of chloroquine in these organs is limited to the eye, skeletal muscle and, more recently, the heart. There have been reports of heart block thought to be due to chloroquine toxicity. ${ }^{8,9}$ Malaria is a common cause of fever in Nigeria and so people falsely attribute all fever to malaria. The majority of such people self-mediate by taking chloroquine.

In this study, we report the consequences for the eye and heart of the indiscriminate intake of chloroquine. Chloroquine abuse leading to chloroquine retinopathy is certainly a common and often unrecognised problem in many tropical countries and there is a need to raise the general level of awareness about the problem.

\section{METHODS}

Twenty-six patients with heart block were studied. There were 18 men and 8 women aged between 38 and 84 years (mean age 55.4 years).

A history of chloroquine intake was taken from each patient to establish past or present chloroquine abuse. All

From: 'Department of Ophthalmology and ${ }^{2}$ Department of Internal Medicine, University of Nigeria Teaching Hospital, Enugu, Enugu State, Nigeria.

Correspondence to: Dr. N. O. Magulike, Department of Ophthalmology, University of Nigeria Teaching Hospital, P.M.B. 01129, Enugu, Enugu State, Nigeria.
26 patients were examined ophthalmologically. The tests done included the measurement of the visual acuity, slit lamp examination, and ophthalmoscopic examination with both the direct and indirect ophthalmoscope. The central visual fields were evaluated with a tangent screen at $2 \mathrm{~m}$ with a $4 \mathrm{~mm}$ red test object. The testing of colour vision was carried out using the Ishihara chart, which is the only colour test available in our unit.

\section{RESULTS}

In this study, chloroquine abuse was defined as that intake of chloroquine which was not within the normal regime for the treatment of malaria. The patients were divided into two groups: group A comprised patients with historical evidence of chloroquine abuse and group B comprised patients without historical evidence of chloroquine abuse.

Chloroquine abuse varied from intramuscular chloroquine $5 \mathrm{ml}$ daily for 2 days, repeated every 2 weeks for 2 years, to 49 tablets of chloroquine fortnightly or monthly for 3 years. One patient took 6 tablets of chloroquine weekly for 6 years. Five modes of chloroquine intake were identified as shown in Table I.

The ophthalmological findings in these patients are shown in Tables II and III. In Table II (group A patients), which also includes the total dose of chloroquine taken per

Table I. Regime of chloroquine intake, duration and cumulative dose

\begin{tabular}{lcc}
\hline Mode of chloroquine intake & Duration & Total dose \\
\hline $\begin{array}{l}\text { 1. IM Chlor. } 5 \mathrm{ml}(=200 \mathrm{mg}) \text { daily for } \\
\quad 2 \text { days, repeated every } 2 \text { weeks }\end{array}$ & 2 years & 20.86 \\
$\begin{array}{l}\text { 2. Tabs. Chlor. } 1500 \mathrm{mg} \text { daily for } \\
\quad 3 \text { days, repeated every month }\end{array}$ & 6 years & 324.00 \\
$\begin{array}{l}\text { 3. Tabs. Chlor. } 1000 \mathrm{mg} \text { start and } \\
1500 \mathrm{mg} \text { daily for } 5 \text { days, }\end{array}$ & 3 years & 663.00 \\
$\begin{array}{l}\text { repeated every fortnight } \\
\text { 4abs. Chlor. } 1000 \mathrm{mg} \text { start and }\end{array}$ & 3 years & 306.00 \\
$\begin{array}{l}1500 \mathrm{mg} \text { daily for } 5 \text { days, } \\
\text { repeated every month }\end{array}$ & & \\
$\begin{array}{l}\text { 5. Tabs. Chlor. } 500 \mathrm{mg} \text { daily for } \\
3 \text { days, repeated every week }\end{array}$ & 6 years & 468.00 \\
\hline
\end{tabular}

IM, intramuscular; Chlor., chloroquine; One Tab. chloroquine = $250 \mathrm{mg}$. 
Table II. Group A: patients with historical evidence of chloroquine abuse

\begin{tabular}{|c|c|c|c|c|c|c|c|c|}
\hline \multirow[b]{2}{*}{ Patient no. } & \multirow[b]{2}{*}{ Age } & \multirow[b]{2}{*}{ Sex } & \multicolumn{2}{|c|}{ Visual acuity } & \multirow[b]{2}{*}{ Fundus findings } & \multirow[b]{2}{*}{ Visual field } & \multirow[b]{2}{*}{ Colour test } & \multirow{2}{*}{$\begin{array}{c}\text { Total } \\
\text { chloroquine } \\
\text { intake }(\mathrm{g})\end{array}$} \\
\hline & & & $\mathrm{R}$ eye & L eye & & & & \\
\hline 1 & 45 & M & $\mathrm{CF}$ & $\mathrm{CF}$ & Bull's eye maculopathy & Central scotoma & Defective & 663.00 \\
\hline 2 & 38 & M & $6 / 12$ & $6 / 12$ & Bull's eye maculopathy & Full & Defective & 324.00 \\
\hline $3^{\mathrm{a}}$ & 56 & M & $\mathrm{HM}$ & $\mathrm{HM}$ & Generalised changes & -- & -- & 663.00 \\
\hline 4 & 47 & M & $6 / 18$ & $6 / 18$ & Generalised changes & Paracentral scotoma & Defective & 663.00 \\
\hline 5 & 44 & M & $6 / 18$ & $6 / 36$ & Generalised changes & - _- & -_- & 663.00 \\
\hline 6 & 52 & M & $6 / 5$ & $6 / 5$ & Normal & Full & Normal & 324.00 \\
\hline $7^{\mathrm{a}}$ & 56 & M & $\mathrm{CF}$ & HM & RP changes & $\ldots$ & -... & 663.00 \\
\hline 8 & 55 & M & $6 / 24$ & $6 / 18$ & Marked maculopathy & $-\ldots-$ & ---- & 468.00 \\
\hline 9 & 44 & M & $6 / 6$ & $6 / 6$ & Normal & Full & Normal & 324.00 \\
\hline 10 & 55 & M & $6 / 9$ & $6 / 9$ & Normal & Full & Defective & 20.80 \\
\hline $11^{\mathrm{b}}$ & 53 & $\mathrm{M}$ & - & - & ---- & --- & 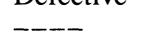 & 306.00 \\
\hline 12 & 60 & M & $6 / 18$ & $6 / 18$ & Stippling of the macula & Constricted & Defective & 324.00 \\
\hline $13^{\mathrm{b}}$ & 66 & M & -- & -- & - & --- & --- & 306.00 \\
\hline
\end{tabular}

$\mathrm{CF}$, counting fingers; HM, hand movement; RP, retinitis pigmentosa.

${ }^{a}$ Visual field and colour test not done because of poor vision.

${ }^{\mathrm{b}}$ Patients did not keep their appointments for ophthalmological examination.

patient, it will be noted that all the 13 patients were males and that they were younger (mean age 51.6 years) than those patients in Table III (group B, mean age 59.2 years). At the time of this study all patients had stopped taking chloroquine on the advice of either an ophthalmologist or a physician. Eight patients had retinal changes. Patients 3, 4 and 5 had bilateral maculopathy, attenuation of the arteries, generalised pigmentary disturbance and pale disc, all of which have been noted in advanced chloroquine retinopathy. ${ }^{2}$ Patients 3 and 7 had very poor vision, as a result of which visual field and colour testing were not done. Patient 5 did not keep the appointment for visual field and colour testing. Patient 8 did not cooperate in the visual field and colour tests. In Table III, patient 1 had bilateral nuclear sclerosis which may have been responsible for the minimal impairment of visual acuity and the depression in the visual field.

\section{DISCUSSION}

The major hazard associated with chronic use of chloroquine is retinopathy. Proximal myopathy with vacuolation of skeletal muscle has also been reported. More recently chronic chloroquine toxicity has been incriminated in the causation of heart block in Africans ${ }^{8}$ and it was recommended that evidence of chloroquine retinopathy should be looked for in these patients.

Stippling of the macula is seen early in chloroquine retinopathy and this may progress to the typical bull's eye configuration or variation in the pigmentary abnormality. Visual fields may be normal or there may be paracentral or pericentral scotomas. ${ }^{10}$ Peripheral constriction of the visual fields as well as impairment of central visual acuity may be present. ${ }^{11}$ Occasionally peripheral pigmentary degeneration similar to that seen in retinitis pigmentosa has been observed. ${ }^{12,13}$

Thirteen of the 26 patients (50\%) in this study gave a positive history of chloroquine abuse; they were all males who wanted to keep good health so that their work would not be disrupted by fever. Eight patients had retinal changes, one of which was due to retinitis pigmentosa. Seven patients $(26.9 \%)$ had retinal changes consistent with chronic chloroquine toxicity.

Bernstein suggested that most cases of retinopathy from chloroquine occur at dosages exceeding $500 \mathrm{mg}$ chlo-

Table III. Group B: patients with no historical evidence of chloroquine abuse

\begin{tabular}{|c|c|c|c|c|c|c|c|}
\hline \multirow[b]{2}{*}{ Patient no. } & \multirow[b]{2}{*}{ Age } & \multirow[b]{2}{*}{ Sex } & \multicolumn{2}{|c|}{ Visual acuity } & \multirow[b]{2}{*}{ Fundus findings } & \multirow[b]{2}{*}{ Visual field } & \multirow[b]{2}{*}{ Colour test } \\
\hline & & & $\mathrm{R}$ eye & L eye & & & \\
\hline $1^{\mathrm{a}}$ & 34 & $\mathrm{~F}$ & $6 / 9$ & $6 / 12$ & Normal & Central depression & - - \\
\hline 2 & 71 & $\mathrm{~F}$ & $6 / 9$ & $6 / 9$ & --- & Full & Normal \\
\hline $3^{\mathrm{b}}$ & 60 & M & $6 / 18$ & $6 / 12$ & ARMD (bilateral) & --- & Defective \\
\hline 4 & 64 & $\mathrm{~F}$ & $6 / 6$ & $6 / 6$ & Normal & Central depression & Defective \\
\hline 5 & 60 & $\mathrm{~F}$ & $6 / 6$ & $6 / 6$ & Normal & Full & Normal \\
\hline 6 & 68 & M & $6 / 9$ & $6 / 9$ & Normal & Full & Normal \\
\hline 7 & 80 & $\mathrm{~F}$ & $6 / 9$ & $6 / 12$ & ARMD (bilateral) & Central depression & Normal \\
\hline 8 & 51 & $\mathrm{~F}$ & $6 / 6$ & $6 / 6$ & Normal & Full & Normal \\
\hline 9 & 70 & $\mathrm{M}$ & $6 / 36$ & $6 / 36$ & Normal & Full & Normal \\
\hline 10 & 56 & $\mathbf{M}$ & $6 / 9$ & $6 / 9$ & Normal & Full & Normal \\
\hline $11^{\mathrm{a}}$ & 60 & $\mathrm{~F}$ & $6 / 36$ & $6 / 6$ & Normal & --- & Defective \\
\hline 12 & 40 & $\mathrm{~F}$ & $6 / 5$ & $6 / 5$ & Normal & Full & Normal \\
\hline 13 & 56 & $\mathbf{M}$ & $6 / 6$ & $6 / 6$ & Normal & Full & Normal \\
\hline
\end{tabular}

ARMD, age-related macular degeneration.

${ }^{\text {a }}$ Patients did not cooperate for visual field and colour tests.

${ }^{\mathrm{b}}$ Patient did not keep appointment for visual field test. 
roquine per day. ${ }^{14}$ However, Easterbrook noted that the risk of chloroquine retinopathy is real and can occur at a dose of $250 \mathrm{mg}$ /day or less. ${ }^{15}$ Sammartino also noted that very few cases of ocular toxicity from chloroquine have been reported in patients receiving a total dosage of less than $300 \mathrm{~g} .{ }^{16}$ In this study only the patient who took a total dose of $20.8 \mathrm{~g}$ (see Table I) had defective colour vision. A colour defect may be detected early in chloroquine retinopathy in spite of a normal fundus. Bishara and Matamoros have also detected early changes of chloroquine toxicity to the retina using a contrast sensitivity test. ${ }^{17}$ The critical daily dose or total dose of chloroquine causing retinopathy has yet to be determined. Ideally a colour vision test should detect the presence or absence of normal colour vision, distinguish between red-green and blueyellow defects (the latter primarily to detect acquired colour vision losses) and assess the severity of any defect. Of the commonly used tests only the American Optical Hardy-Rand-Rittler plates satisfy all of these requirements. However, similar results can be obtained using the Ishihara pseudoisochromatic plates and the Farmsworth panel D-15 in combination. ${ }^{18}$

In conclusion, chronic chloroquine overdose and toxicity is an important aetiological factor in heart block in Africans and the historical as well as ophthalmological confirmation should be sought in all patients presenting with heart block.

We are grateful to Professor A. R. Elkington for his advice and to Miss Wendy A. Williams and Mrs. C. U. Ijemba for typing this manuscript.

Key words: Chloroquine retinopathy, Heart block.

\section{REFERENCES}

1. Hobbs HE, Sorsby A, Freedman A. Retinopathy following chloroquine therapy. Lancet 1959;2:478-80.
2. Brinkley JR, Dubois EL, Ryan SJ. Long-term course of chloroquine retinopathy after cessation of medication. Am J Ophthalmol 1979;88:1-11.

3. Hobbs HE, Eadie SP, Somerville F. Ocular lesions after treatment with chloroquine. Br J Ophthalmol 1961;45: 284-97.

4. Okun E, Gouras P, Bernstein H. Chloroquine retinopathy: a report of eight cases with ERG and dark adaptation findings. Arch Ophthalmol 1964;69:738-44.

5. Carr RE, Henkind P, Rothfield N. Ocular toxicity of antimalarial drugs. Am J Ophthalmol 1968;66:738-44.

6. Nylander U. Ocular damage in chloroquine therapy. Acta Ophthalmol (Copenh) 1967;(Suppl)92:1-71.

7. Amoni SS, Pattern of macular diseases in Nigeria: a preliminary report. Ann Ophthalmol 1983;15:384-8.

8. Oli JM, Ihenacho HNC, Talwar S. Chronic chloroquine toxicity and heart block: a report of two cases. East Afr Med J 1980;57:505-7.

9. Ladipo GAA, Essien EE, Andy JJ. Compete heart block in chronic chloroquine poisoning. Int $\mathbf{J}$ Cardio 1985;4: 198-200.

10. Crews SJ. Chloroquine retinopathy with recovery in each stage. Lancet 1964;2:436-8.

11. Scherbel AL, Mackenzie AH, Noursak JE, Atdjian M. Ocular lesions in rheumatoid arthritis and related disorders with particular reference to retinopathy. N Engl J Med 1965; 273:360-6.

12. Editorial. Chloroquine and the eye. Lancet 1964;1:423-4.

13. Henkind P, Carr RE, Siegel IM. Early chloroquine retinopathy: clinical and functional findings. Arch Ophthalmol 1964;71:157-65.

14. Bernstein HM. Ophthalmologic considerations and testing in patients receiving long term antimalarial therapy. Am J Med (Suppl) 1983;75:25-34.

15. Easterbrook M. Dose relationships in patients with early chloroquine retinopathy. J Rheumatol 1987;14:472-5.

16. Sammartino JP, Soll DB. Ocular toxicity of systemic drugs. AFP Clin Pharmacol 1985;31:226-9.

17. Bishara SA, Matamoros N. Eye 1989;3:777-82.

18. Basic and clinical science course sect 4: Retinal and vitreous. American Academy of Ophthalmology, 1987/8:90-1. 